УДК 338.2/ 553.493

$10.17213 / 2075-2067-2021-1-188-202$

\title{
ОРГАНИЗАЦИОННО-ЭКОНОМИЧЕСКИЕ МОДЕЛИ РАЗВИТИЯ РЕДКОЗЕМЕЛЬНЫХ ПРОМЫШЛЕННЫХ КОМПЛЕКСОВ: РОССИЙСКИЙ И ЗАРУБЕЖНЫЙ ОПЫТ ${ }^{1}$
}

\author{
(C) 2021 г. В. М. Соловьева, А. Е. Череповицын
}

\section{Санкт-Петербургский горный университет, г. Санкт-Петербург, Россия}

Целью исследования является анализ зарубежного и отечественного опыта развития редкоземельных промышленных комплексов для формирования целостных представлений о сложившихся моделях и используемых странами механизмах развития РЗМ-отрасли с учетом современных тенденций глобального рынка.

Методологическая основа исследования. Для достижения поставленных задач был проведен контент-анализ национальных и зарубежных источников научной литературы, государственных отчетов и стратегий в отношении развития редкоземельной отрасли, материалов аналитических агентств, посвященных обзору современных тенденций на рынке РЗМ. Исследована концепџия РЗМ-металлов как «критических» материалов для современной экономики. В работе использованы методы научного обобщения, системного и стратегического анализа.

Результаты исследования. В статье исследовань тенденции мировой редкоземельной отрасли, структура и динамика развития мирового рынка металлов, обоснована роль редкоземельных металлов для современной экономики в условиях наращивания научно-технического потенциала. Выявлены ключевые экономические, технологические, производственные, геологические особенности и ограничения создания РЗМ-производств. Исследованы сложившиеся организачионно-экономические модели развития редкоземельных промышленных комплексов в рамках достижения обеспеченности в требуемых ресурсных компонентах, систематизированы используемые различными странами методы и механизмы, к которым относятся меры налогового стимулирования, финансирование научно-исследовательских работ, заключение долгосрочных контрактов и другие. Сформированы рекомендации относительно развития РЗМ-комплексов в России.

Перспективы исследования состоят в возможности использования рассмотренных моделей и механизмов развития зарубежных редкоземельных комплексов для повышения эффективности функционирования российской РЗМ-отрасли.

Ключевые слова: редкоземельные металль; промышленные комплексы; критические материаль; механизмы; российский и зарубежный опыт.

1 Статья подготовлена на основе научных исследований, выполненных при финансовой поддержке гранта РНФ, проект №19-78-00108 «Стратегическое прогнозирование развития промышленно-сырьевых комплексов в Арктике». 


\title{
ORGANIZATIONAL AND ECONOMIC MODELS OF RARE EARTH INDUSTRIAL COMPLEXES' DEVELOPMENT: RUSSIAN AND FOREIGN EXPERIENCE
}

\section{(C) 2021 V. M. Solovyova, A. E. Cherepovisyn}

\author{
Saint Petersburg Mining University, Saint Petersburg, Russia
}

The aim of the study is to analyze the Russian and foreign experience of rare earth industrial complexes' development in order to create a comprehensive picture of the models formed and mechanisms applied by different countries for REE industry development taking into consideration key tendencies of the global market.

The methodological basis. To achieve the objectives of the research a content-analyzes of national and foreign sources of academic literature, of the governmental reports and strategies within rare earth industry's development, of the analytical agencies' materials devoted to the view of REE market's tendencies has been provided. The concept of rare earths as «critical» materials for the modern economics has been investigated. The methods of the scientific generalization, systematic and strategic analyses have been applied.

Results of the study. The key trends, the structure and dynamics of the global rare earth market have been investigated. The role of rare earths for the world economics in a view of the technological advances has been sustained. The main economic, technological, pro-duction, geological features and limitations of the REE earth production volumes' development have been identified. The existing organizational and economic models of the rare-earth industrial complexes' development have been investigated within the ensurance of security in the required resource components. Methods and mechanisms used by various countries have been systematized. These include tax incentives, funding of research work, signing of long-term contracts, and others. Recommendations for the development of REE complexes in Russia have been formulated.

Prospects of the research are in the possibility of the considered models and mechanisms of foreign rare earth complexes applying to improve the efficiency of the Russian rare earth industry.

Key words: rare earth metals; industrial complexes; critical materials; mechanisms; Russian and foreign experience.

Введение. Обеспеченность редкоземельными металлами (РЗМ) является одним из важных факторов, определяющих уровень научно-технологического прогресса государств, стремящихся к лидерству на мировом рынке высоких технологий [17]. Современный рынок РЗМ считается одним из самых быстроразвивающихся и динамичных товарных рынков $[1,3]$. Благодаря своим уникальным свойствам данные металлы стали неотъемлемыми составляющими современных технологий в области авиастроения, робототехники, электроники, атомного энергетического комплекса, цифровой индустрии, «зеленой» энергетики и многих других [19-20].
Однако, несмотря на безусловную значимость редкоземельных металлов для экономики развитых стран мира, далеко не все государства могут самостоятельно обеспечить потребности в необходимых РЗМ, что обусловлено не только ситуацией, сформировавшейся на глобальном рынке, но и особенностями создания и развития редкоземельных промышленных комплексов, связанными с высокими геологическими, технологическими, экономическими и экологическими рисками [2, 10]. В отличие от Китая, США и Австралии, такие государства, как Япония, Южная Корея и страны Европейского союза (ЕС), не имеют прямого доступа к сырьевым ресурсам РЗМ, 
что предопределяет существование различий в выстраиваемых странами организационноэкономических моделях и используемых механизмах развития отрасли [30].

Важно отметить, что несмотря на значительный ресурсный потенциал в России сохраняется высокая степень импортозависимости от поставок редкоземельных металлов [7]. Для формирования представлений о возможностях развития отечественной редкоземельной отрасли целесообразно обратиться к опыту зарубежных стран в области создания РЗМ-комплексов, рассмотреть реализуемые модели, используемые методы, формы и механизмы развития таких комплексов с целью достижения ресурсной обеспеченности в требуемых компонентах и наращивания экспортного потенциала.

\section{1. Современные тенденции глобальной} редкоземельной отрасли. На сегодняшний день ресурсная обеспеченность считается важнейшим экономическим и политическим фактором общественного производства. Доступ к ресурсам является предметом конкурентной борьбы на уровне стран мира, и если ранее основная борьба разворачивалась преимущественно за энергетические ресурсы, то сегодня их место постепенно занимают металлы, в частности РЗМ [11]. По данным Zion Market Research, ежегодный темп роста глобального рынка редкоземельных метал- лов составляет 6-8\%, а вся готовая продукция на основе РЗМ оценивается в 1,5-2 трлн. долл., что фактически соответствует 10-12\% объемов всей мировой торговли [17].

Мировой спрос на РЗМ непрерывно возрастает, что связано со стремительным расширением областей применения данных элементов в высокотехнологичных отраслях промышленности $[11,12,18]$. Главным драйвером считается сектор «зеленой» энергетики, прогрессивное развитие которого связано с принятием новых инициатив в области экологической безопасности, трансформацией мирового энергетического сектора и утверждением в 2016 году условий Парижского соглашения, регламентирующего необходимость снижения углекислого газа в атмосфеpe $[18,22]$. На рисунке 1 представлены сведения о динамике мирового спроса на РЗМ в период до 2040 года с учетом прогнозируемого объема производства электромобилей.

При этом обеспечение спроса в необходимых РЗМ для многих государств мира представляется сложной задачей ввиду того, что создание и развитие собственных редкоземельных промышленных комплексов связано со следующими особенностями и ограничениями $[3,7,10]$ :

1) геологические: низкие промышленные концентрации редкоземельных компонентов в рудах, рассеянный характер распределения, диспропорции содержания подгрупп легких

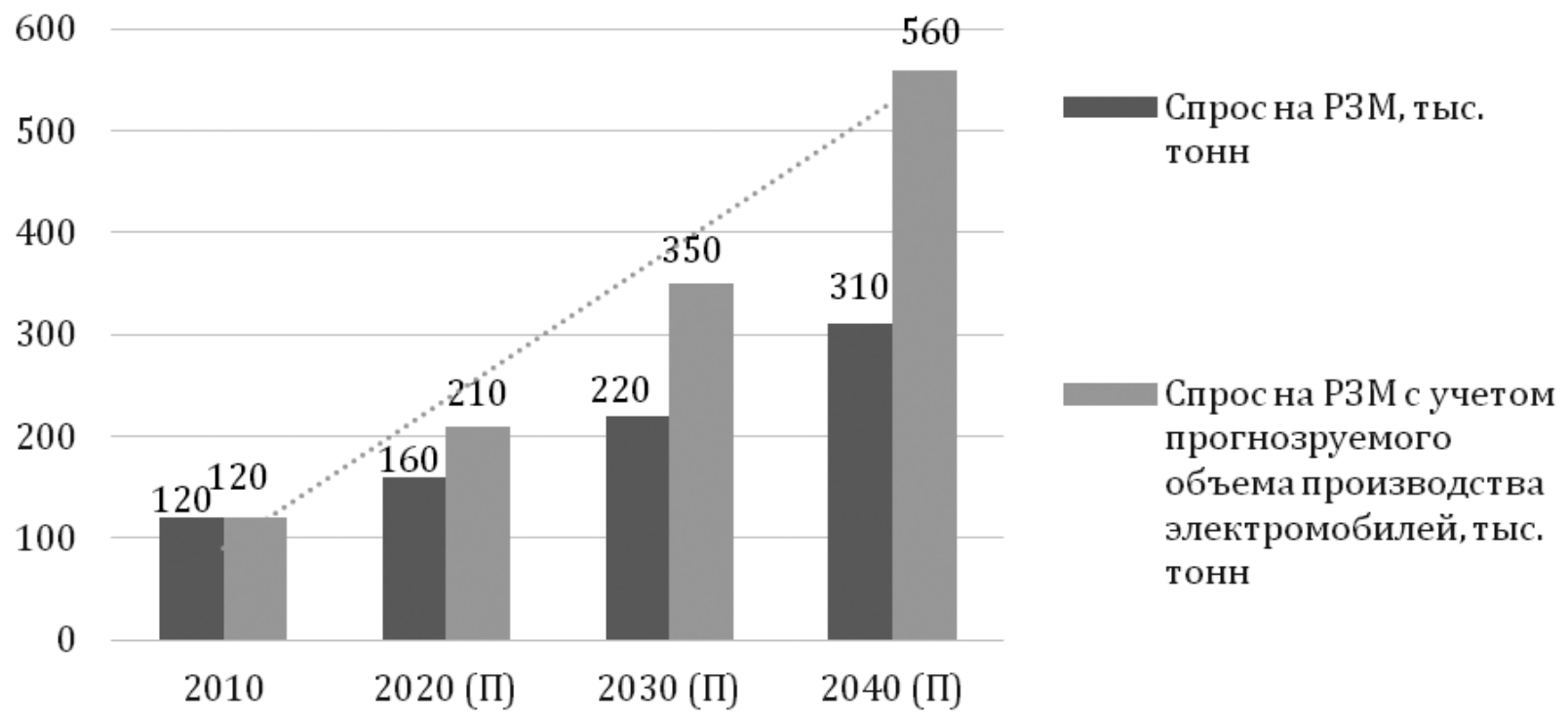

Рис. 1. Прогнозируемая динамика глобального спроса на редкоземельные металлы, тыс. тонн (П - прогнозируемые значения показателей) [16] 
и тяжелых элементов, трудности в проведении лабораторных исследований;

2) технологические: необходимость разработки и внедрения уникальных технологий, методов и способов переработки минерального сырья с целью извлечения редкоземельных компонентов и конечной РЗМ-продукции;

3) производственные: сложность и многостадийность производства редкоземельной продукции (от получения первичных концентратов до готовой продукции высокой добавленной стоимости - магниты, оксиды);

4) экономические: высокая капиталоемкость и сравнительно низкая экономическая эффективность создания редкоземельных производств, невысокая инвестиционная привлекательность РЗМ-проектов, существенные различия в стоимости продукции ирstream и down-stream сегментов;

5) экологические: ряд редкоземельных металлов обладает радиоактивными свойствами, что обуславливает повышенные экологические риски на этапе их промышленного освоения.

Главным монополистом мировой редкоземельной отрасли остается Китай [1, 29]. Редкоземельный кризис, сложившийся на рубеже 2010-2012 годов, доказал высокую степень зависимости государств от внешнеторговой политики, реализуемой данной страной в отношении поставок металлов и РЗМ-продукции и «заставившей» многие государства, в частности Японию, США, Австралию и страны Европейского союза (ЕС), пересмотреть подходы к проводимой минерально-сырьевой политике [13-14]. В целом ряде стран редкоземельные металлы были отнесены к «критическим» и «стратегическим» видам минерального сырья [2].

Согласно трактовке ЕС критические виды минерального сырья - это ресурсы, имеющие не только стратегическую значимость для экономики, но и обладающие высоким уровнем риска цепочки поставок, под которым понимается вероятность того, что отдельные виды минерального сырья по различным причинам станут недоступными [14]. Отнесение РЗМ к стратегическим видам минерального сырья связано с их использованием при создании приборов, конструкций, технологий и техники в сфере военной промышленности. Соответственно, можно кон- статировать, что отсутствие доступа к требуемым РЗМ может оказать отрицательное воздействие на экономическую безопасность развитых государств мира $[8,24]$. Это объясняет нацеленность стран на нивелирование рисков зависимости от импорта металлов из Китая.

В 2019-2020 годах, несмотря на сохраняющуюся доминирующую позицию Китая, число производителей, занимающихся выпуском РЗМ и редкоземельной продукции в мире, возросло, что сказалось на структуре глобального рынка - если доля Китая в структуре мирового производства РЗМ в 2015 году составляла $84 \%$, то в 2019 году лишь $62 \%$ [29]. В качестве новых «игроков» на мировом рынке металлов выступили США, где была возобновлена деятельность по добыче РЗМ в Маунтин-Пасс, и Австралия, объемы выпуска редкоземельных металлов которой в 2019 году достигли 21 тыс. тонн (в пересчете на оксиды).

Приоритеты государственной политики России также нацелены на форсированное развитие отечественной РЗМ-промышленности для обеспечения устойчивости функционирования высокотехнологичных отраслей национальной промышленности, что обозначено в Проекте «Стратегии развития отрасли редких и редкоземельных металлов Российской Федерации на период до 2035 года» [6]. Страна, наряду с Китаем, Австралией и США, имеет доступ к значительной ресурсной базе РЗМ, однако доля России в структуре мирового производства металлов не превышает 2\% [29].

Формируемые сегодня тенденции позволяют сделать вывод о том, что в среднесрочной перспективе глобальный рынок редкоземельных металлов продолжит развиваться быстрыми темпами, несмотря на то, что сама структура рынка может претерпеть изменения ввиду усиления конкурентной борьбы, направленной на смещение позиции главного монополиста мировой отрасли $[15,17,29]$. Нестабильное положение рынка РЗМ и стремительный рост спроса на данные виды металлов открывают широкие возможности для развития редкоземельных промышленных комплексов за пределами Китая. Изучение опыта зарубежных стран может стать основой для принятия стратегии и выбора дейс- 
твенных механизмов развития таких комплексов в России.

2. Подходы к развитию редкоземельных промышленных комплексов. На сегодняшний день можно условно выделить две организационно-экономические модели развития редкоземельных промышленных комплексов и обеспечения экономики требуемыми видами критических материалов, в основе которых лежит параметр наличия/отсутствия доступа к минеральносырьевой базе.

Первая модель, главными представителями которой являются Япония, Южная Корея, государства Европейского Союза (Франция, Германия, Бельгия и т.д.), связана с созданием устойчивой цепочки импорта готовой продукции и организацией производств в сегменте down-stream, что объясняется отсутствием прямого доступа к сырьевым компонентам. Основными стратегическими альтернативами в рамках обозначенной модели являются [19-21, 30]:

- обеспечение поставок требуемых видов РЗМ путем заключения долгосрочных контрактов с мировыми поставщиками металлов;

- поиск производственных возможностей: исследование альтернативных источников получения редкоземельных металлов, разработка технологий извлечения РЗМ из техногенных отходов и пр. [25];

- поиск материалов, способных своими свойствами заменить редкоземельные металлы (альтернативные материалы);
- участие в зарубежных проектах, связанных с разработкой месторождений редкоземельного сырья (к примеру, Япония является участником РЗМ-проектов во Вьетнаме, Киргизии, Индии и Казахстане);

- ориентация на долгосрочное планирование и прогнозирование обеспечения экономики требуемыми видами критических материалов [14].

Особое внимание уделяется разработке технологий рециклинга, нацеленных на извлечение редкоземельных компонентов из утилизируемых изделий, например, аккумуляторов, отходов электроники, батарей из гибридных автомобилей и т.д. (таблица 1).

Несмотря на наличие технологий, рециклинг позволяет производить лишь небольшие объемы продукции, недостаточные для удовлетворения растущего спроса. Так, согласно структуре экспорта Китая, основными импортерами являются Япония и Южная Корея. По данным 2019 года, в Японию было импортировано 4,9 тыс. тонн церия, 3,3 тыс. тонн лантана, 1,5 тыс. тонн иттрия, при этом объемы поставок ежегодно увеличиваются [15]. В настоящее время в стране стимулируются исследования, направленные на поиск альтернативных материалов, сопоставимых по качеству с Р3М [11]. Так, в 2013 году велась разработка новых элементов, способных заменить самарий в современных магнитах, что было связано с наличием острого дефицита данного металла на рынке. В результате продолжительных исследований японским ученым удалось создать новый магнит с ана-

Таблица 1

Технологии рециклинга РЗМ, используемые зарубежными странами $[5,9,27]$

\begin{tabular}{|c|c|c|c|}
\hline \multirow{2}{*}{ Страна } & $\begin{array}{c}\text { Компания- } \\
\text { разработчик }\end{array}$ & $\begin{array}{c}\text { Утилизируемые РЗМ-изделия } \\
\text { (согласно используемой технологии) }\end{array}$ & Виды извлекаемых РЗМ \\
\hline \multirow{2}{*}{ Япония } & Hitachi & $\begin{array}{c}\text { Магниты из воздушных } \\
\text { кондиционеров, компрессоров }\end{array}$ & $\mathrm{Nd}, \mathrm{Pr}, \mathrm{Dy}$ \\
\cline { 2 - 5 } & Honda, Toyota & Батареи из гибридных автомобилей & $\mathrm{Nd}, \mathrm{La}$ \\
\cline { 2 - 5 } & Kosaka Smelting & Отходы электроники & $\mathrm{Nd}, \mathrm{Dy}$ \\
\hline Бельгия & Umicore & Никель-металл-гибридные батареи & $\mathrm{Nd,} \mathrm{La}$ \\
\hline \multirow{2}{*}{ Франция } & Rhodia & Никель-металл-гибридные батареи & $\mathrm{Nd}, \mathrm{La}$ \\
\cline { 2 - 5 } & Veolia & Аккумуляторы, компьютеры & $\mathrm{Ce}, \mathrm{La}, \mathrm{Y}, \mathrm{Nd}, \mathrm{Gd}, \mathrm{Eu}, \mathrm{Tb}$ \\
\hline Германия & OSRAM & Люминесцентные лампы & $\mathrm{Ce}, \mathrm{La}, \mathrm{Y}, \mathrm{Nd}, \mathrm{Gd}, \mathrm{Eu}, \mathrm{Tb}$ \\
\hline
\end{tabular}


логичными свойствами за счет добавления другого компонента - диспрозия, также относящегося к редкоземельным металлам. Можно заключить, что изобретатели в области высоких технологий фактически предпринимают лишь попытки к замене использования одних РЗМ (с более высоким риском поставок) на другие (с приемлемым/низким уровнем риска поставок) [11]. Заменить же данные материалы альтернативными источниками пока не представляется возможным.

Очевидно, что дефицит редкоземельных металлов может оказать влияние на устойчивость и динамику развития высокотехнологичных отраслей промышленности, ввиду чего страны, не имеющие доступа к ресурсам, вынуждены искать альтернативные варианты обеспечения экономики в требуемых РЗМ, особенно в условиях имеющихся геополитических угроз.

Вторая модель, к которой можно отнести Китай, США и Австралию, предполагает формирование и развитие собственных производств по выпуску РЗМ и редкоземельной продукции. Основой данной модели является доступ к соответствующим сырьевым ресурсам. Наиболее распространенной стратегией среди стран-лидеров РЗМ-рынка, позволившей добиться значительных результатов на глобальном рынке, стала стратегия «от шахты до магнита», основанная на формировании вертикально-интегрированных комплексов и крупных госкорпораций. При этом, как было отмечено ранее, создание собственных редкоземельных промышленных комплексов сопряжено с высокими геологическими, технологическими и экономическими рисками, исходящими из особенностей реализации РЗМ-проектов [19-20, 30].

В данном случае интересно рассмотреть стратегию Австралии в отношении создания промышленно-сырьевых комплексов. Основные усилия страны направлены на поддержание геологоразведочного и добывающего секторов за счет государственного финансирования геологоразведки, предоставления субсидий и специальных кредитов недропользователям уже на начальных этапах освоения ресурсов [19, 24]. Одновременно с этим государство предпринимает меры по стимулированию организации производств редкоземельной продукции более высокой добав- ленной стоимости за счет привлечения зарубежных компаний и инвесторов к осуществлению редкоземельных проектов. Основной упор делается в сторону развития технологической составляющей, совершенствование которой позволило Австралии запустить ряд Р3М-проектов, ставших конкурентоспособными в условиях мирового рынка [19].

Политику США в отношении развития редкоземельной отрасли можно назвать двойственной. С одной стороны, государство нацелено на форсированное развитие национальной промышленности, с другой же на формирование альтернативных поставок P3М из третьих стран (государств за исключением Китая) для нивелирования вероятных рисков организации собственных производств. В стране главный акцент сделан также на совершенствовании технологической составляющей - финансировании научно-исследовательской деятельности, развитии научно-технических программ, усилении взаимосвязи между университетами и компаниями. Разрабатываемые технологии охватывают не только сектор добычи, но и сектор вторичной переработки, который также стимулируется за счет различных форм государственного финансирования [8, 29].

Исходя из рыночной ситуации, наиболее успешным можно считать комплексный подход, реализуемый Китаем. Достижение доминирующего положения на рынке металлов было обусловлено активизацией геологоразведочных и добывающих работ, главной технико-экономической установкой которых стало обеспечение комплексного использования ресурсов недр на основе разработки и внедрения уникальных технологий комплексного использования минерального сырья и обогащения руд. В Китае на законодательном уровне были закреплены положения о комплексных изысканиях, комплексной оценке и освоении рудных месторождений [11]. Одновременно с этим была сформирована эффективная система «поощрения» недропользователей при освоении полезных ископаемых низкого качества, труднообогатимых руд, вторичного сырья и пр., что существенно расширило потенциальные источники извлечения редкоземельных компонентов. Также были введены стимулирующие меры по развитию сегмента down-stream, что позволило 
Китаю выстроить целостную технологическую цепочку производства редкоземельной продукции и снизить до минимума риски, относящиеся к обеспечению национальной экономики и промышленности необходимыми РЗМ-компонентами [15].

Организационно-экономические модели развития отрасли в Китае формируются, исходя из сложностей редкоземельной отрасли на каждом конкретном производственном этапе. Первоначально китайская промышленность состояла из множества локальных производителей, деятельность которых фактически не поддавалась контролю. Это привело к интенсификации нелегальной добычи и, как следствие, к существенным потерям бюджета государства, ввиду чего страна переориентировалась на новую бизнес-модель - создание вертикально-интегрированных промышленных комплексов. Главной стимулирующей мерой их выстраивания стало ограничение экспорта отдельных видов продукции. Так, ограничение экспорта концентрата, с одной стороны, сузило возможности компаний ориентироваться только на продажу продукции после первых этапов обработки, а с другой — обеспечило ресурсный базис для реализации последующих технологический стадий.

Проводимая в настоящее время промышленная политика Китая ориентирована на удержание всей цепочки производства и добавленной стоимости наукоемкой продукции на основе организации редкоземельных промышленных комплексов внутри страны. С целью регулирования как национального, так и глобального рынка РЗМ в 2009-2012 годах в Китае были созданы хранилища легких (в Баотоу) и тяжелых металлов (Южный Китай). В период 2012-2013 годов в Государственный резерв было направлено более 20 тыс тонн редкоземельных металлов в пересчете на оксиды [11-15].

Интересным фактом является то, что Китай, несмотря на ужесточение политики в отношении экспорта редкоземельной продукции, не исключает возможности допуска иностранных компаний к частичному финансированию РЗМ-проектов. Многие зарубежные компании, работающие в отрасли высоких технологий (Япония, Корея), были вынуждены передислоцировать производс- твенные мощности на территорию Китая на особых условиях с целью получения доступа к требуемым сырьевым компонентам. Для экономики Китая это стало возможностью притока инвестиций в экономику и расширения степени влияния на деятельность иностранных производителей [11].

Что касается России, то страна, как было отмечено ранее, обладает существенным ресурсным потенциалом и, по данным 2019 года, занимает четвертое место в мире по объемам учтенных запасов РЗМ. Это условие позволяет отнести страну к модели, следуемой Китаем, США и Австралией. В то же время, в отличие от выше приведенных государств, реализуемые в России механизмы нацелены только на up-stream сегмент - добычу и первичное получение концентратов. Так, были введены льготы по налогу на добычу полезных ископаемых (НДПИ), финансируется проведение геологоразведочных работ. Однако отсутствие производств по выпуску продукции более высокой добавленной стоимости в существенной мере ограничивает возможности России как в плане обеспечения собственных потребностей в РЗМ, так и в рамках наращивания экспортного потенциала [7, 23, 28]. Единственным источником получения редкоземельных компонентов в России остается Ловозерское месторождение. Запуск прочих потенциально перспективных проектов (освоение Африкандского, Томторского, Селигдарского месторождений), согласно данным Министерства промышленности и торговли РФ, планируется не раннее 2025 года $[4,6]$.

В таблице 2 обобщены подходы к развитию редкоземельных промышленных комплексов.

Можно заключить, что, несмотря на существующие различия в организационноэкономических моделях, главной целью реализуемых развитыми странами стратегий в отношении развития редкоземельных комплексов является снижение уровня зависимости высокотехнологичных отраслей промышленности необходимыми видами РЗМ в долгосрочной перспективе. Наиболее устойчивой можно считать модель, реализуемую США, Китаем и Австралией, потребление редкоземельных металлов которых обеспечивается за счет собственных производственных мощностей, что исключает возможность 


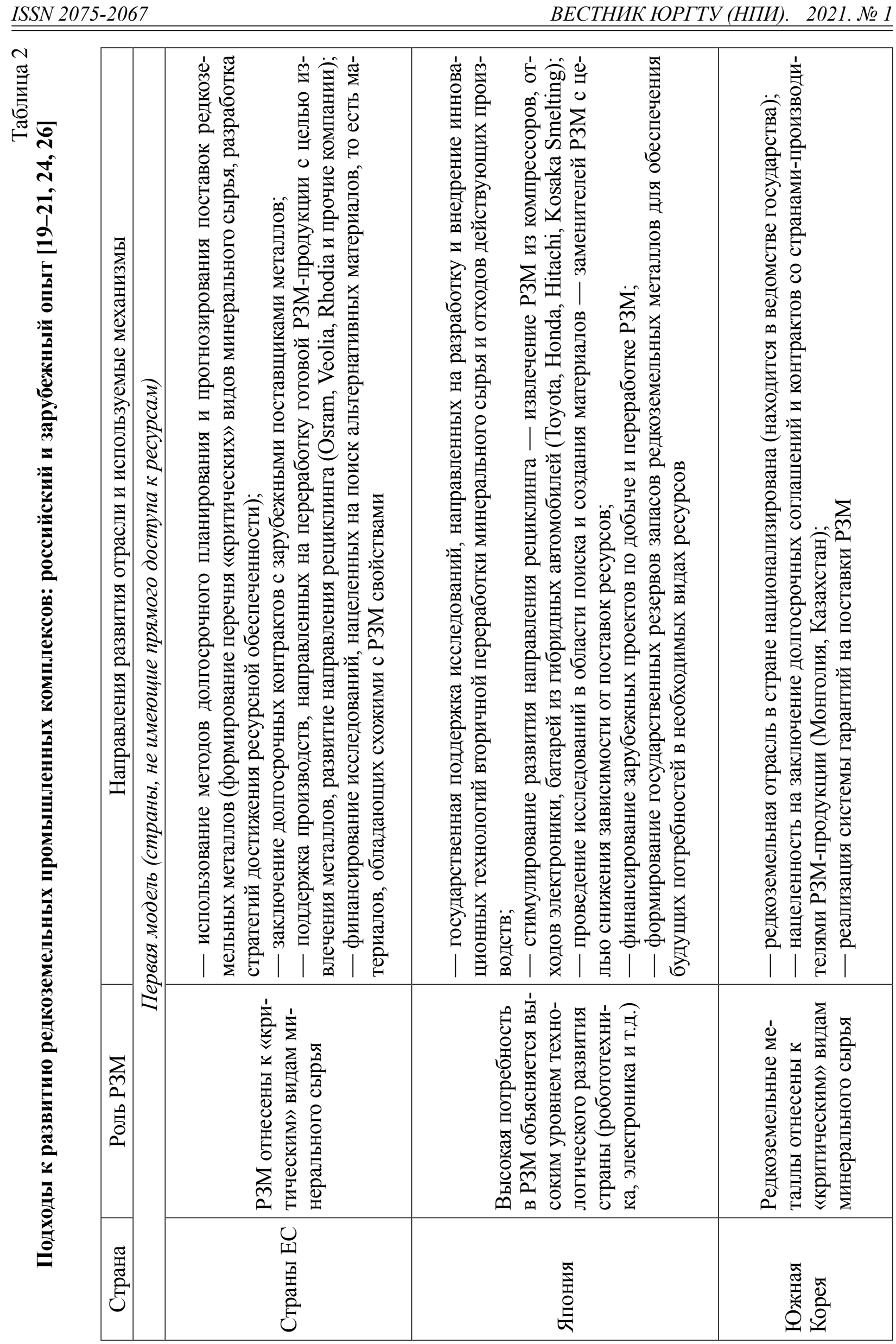




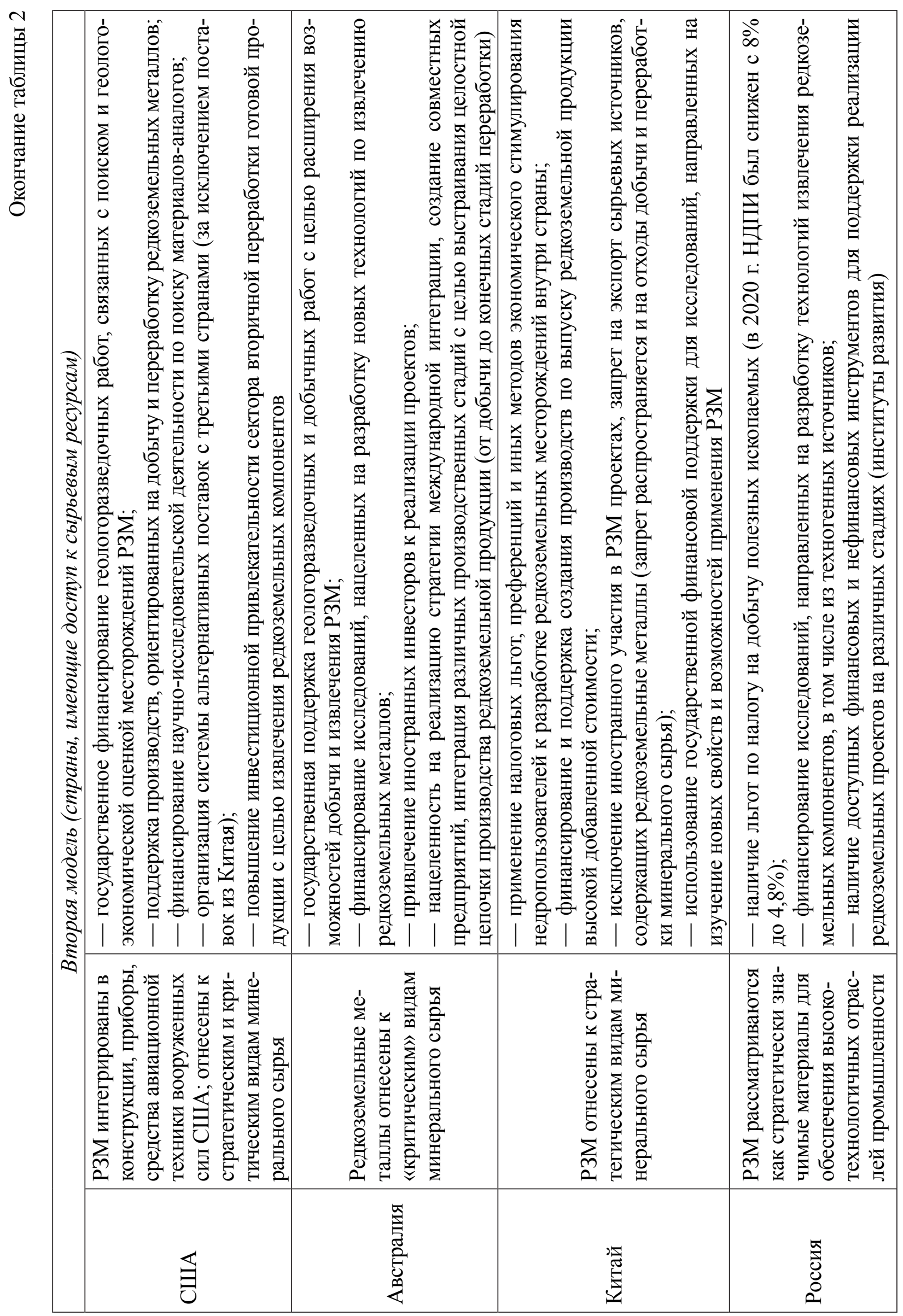


влияния геополитических факторов на наличие доступа к требуемым компонентам.

Основные механизмы, используемые государствами для поддержки и развития РЗМотрасли, включают в себя финансирование научно-исследовательских работ, стимулирование проведения геологоразведочных работ (рисунок 2). Важно отметить, что реализуемые странами, имеющими доступ к ресурсам, меры направлены как на поддержание сектора добычи, так и на стимулирование развития стадий более высокого передела готовой продукции. Это объясняется тем, что продукция up-stream сегмента фактически не востребована на современном рынке высоких технологий. Концентраты имеют ограниченную область использования и нуждаются в дальнейшей переработке, ввиду чего для устойчивого развития редкоземельных промышленных комплексов очевидна необходимость применения системного подхода, хорошим примером реализации которого является именно Китай.

Важно также отметить, что зарубежные подходы к решению проблем производства/ поставки РЗМ характеризуются высоким долевым участием государства в финансировании соответствующих стратегий $[4,27]$.

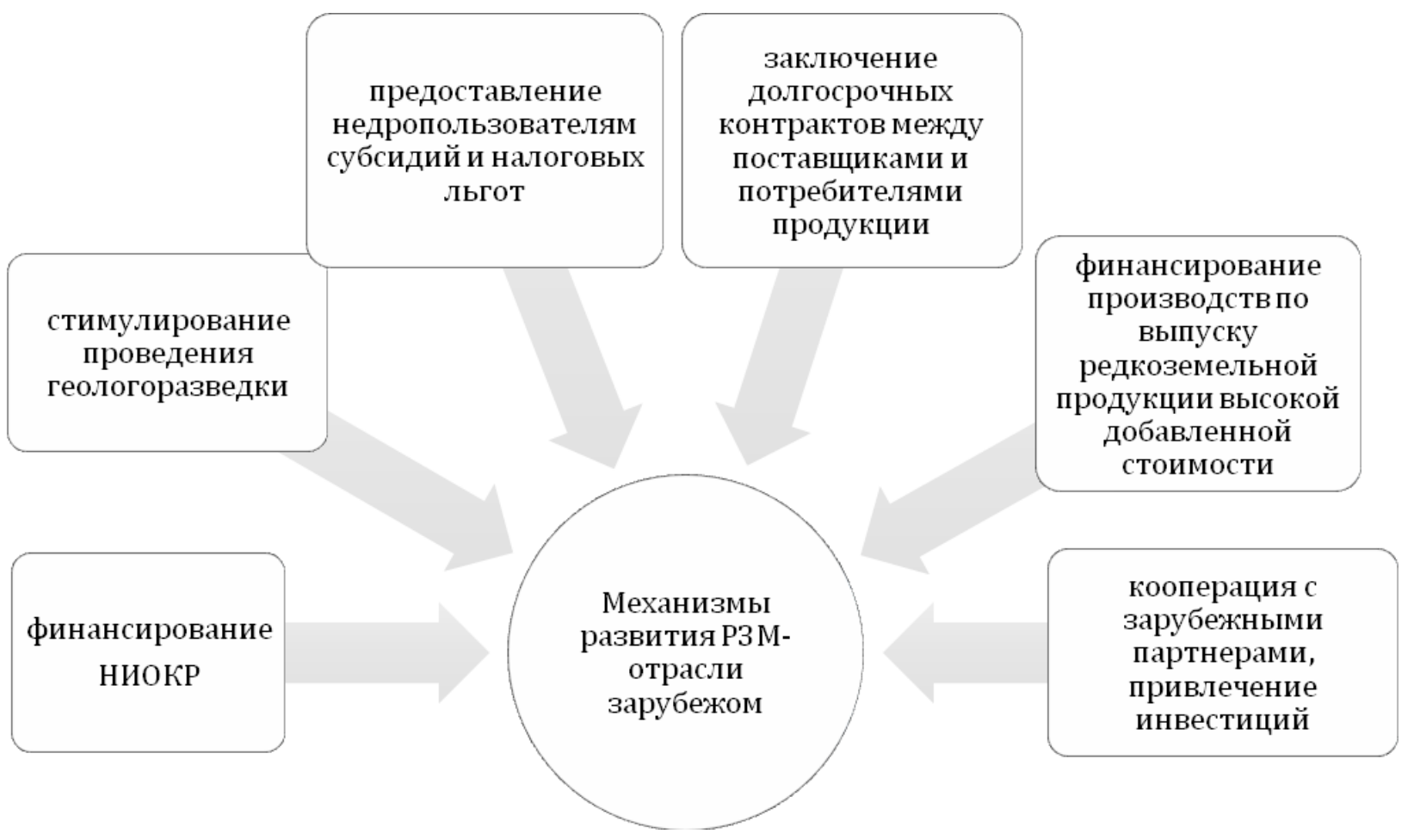

Рис. 2. Механизмы развития редкоземельной отрасли, используемые зарубежными странами
В целом можно сделать вывод о том, что для России как для страны, имеющей доступ к сырьевым ресурсам, целесообразно реализовывать на практике модель развитых стран (Китай, США, Австралия) с целью предотвращения фрагментарного характера разви-

На основе анализа опыта зарубежных стран можно выделить следующие рекомендации для развития РЗМ-комплексов в нашей стране:

- обеспечение системного характера реализуемых механизмов - дифференцированная система мер поддержки и стимулирования на различных этапах производственного цикла (субсидии, налоговые льготы);

- пересмотр мер тарифного и нетарифного регулирования экспорта первичной продукции - концентратов, отходов производств, введение соответствующих ограничений;

- стимулирование создания производств по выпуску РЗМ-продукции высокой добавленной стоимости (оксиды, разделенные металлы, используемые в высокотехнологичных отраслях промышленности);

- рассмотрение возможности допуска иностранных инвесторов к финансированию реализуемых редкоземельных проектов;

долгосрочных
контрактов между
поставщиками и
потребителями
продукции

финансирование виводств выпуску совавленной стоимости кооперация с зарубежными партнерами, привлечение инвестиций тия отрасли. 
- реализация имеющегося потенциала государственных мер поддержки применительно к РЗМ-производствам (институты развития, венчурное финансирование);

- финансирование научных исследований, нацеленных на создание и совершенствование технологий переработки и извлечения редкоземельных компонентов, рассмотрение возможности развития технологий рециклинга с целью обеспечения дополнительного прироста выпуска РЗМ.

Заключение. Таким образом, были исследованы ключевые тенденции на мировом рынке РЗМ, обоснована значимость данных компонентов для глобальной экономики. В современных условиях решение проблем обеспечения экономики и промышленности необходимыми РЗМ - это вызов, от грамотного разрешения которого во многом зависит научно-технический прогресс стран в развивающихся отраслях «зеленой» энергетики, низкоуглеродного развития и пр., а также лидерство на глобальном рынке высоких технологий.

Приоритеты развитых стран нацелены на достижение ресурсной обеспеченности в требуемых сырьевых компонентах и снижение уровня зависимости от поставок из Китая как главного монополиста отрасли. С целью нивелирования геополитических рисков целый ряд государств начал предпринимать активные действия по созданию собственных производств выпуска редкоземельной продукции. В то же время создание РЗМ промышленных комплексов представляется сложнейшей задачей, связанной с повышенными экономическими и технологическими рисками. Более того, далеко не все страны, развивающие высокотехнологические сектора экономики, имеют прямой доступ к минерально-сырьевой базе редких металлов. Все это в условиях сохраняющейся монополии на мировом рынке формирует неопределенность в выборе стратегий развития отрасли.

На основе проведенного анализа было выделено две организационно-экономические модели развития редкоземельных промышленных комплексов и обеспечения экономики требуемыми видами критических материалов, в основе которых лежит параметр наличия/отсутствия доступа к соответс- твующей минерально-сырьевой базе. Опыт зарубежных стран в отношении развития редкоземельных промышленных комплексов свидетельствует о необходимости системного подхода к реализации мер и механизмов поддержки отрасли с целью повышения инвестиционной привлекательности проектов, создания технологического задела и т.д. Сформированные на основе проведенного исследования рекомендации могут стать необходимыми условиями воссоздания российской редкоземельной промышленности.

\section{Литература}

1. Гасанов А.А., Наумов А.В., Юрасова О. В., Петров И. М., Литвинова Т. Е. Некоторые тенденции мирового рынка РЗМ и перспективы России // Известия вузов. Цветная металлургия. - 2018. - №4. - С. 31-44.

2. Еремин Н.И. Критическое минеральное сырье в экономиках ведущих промышленно-развитых стран // Материалы конференции «Месторождения стратегических металлов», ИГЕМ РАН. - 2015. - С. 48-56.

3. Кондратьев В.Б. Глобальный рынок редкоземельных металлов // Горная промышленность. - 2017. — №4 (134). — С. 97-119.

4. Минпромторг РФ. Официальный сайт [Электронный ресурс]. - Режим доступа: https://gisp.gov.ru/new_user/ (Дата обращения: 12.12.2020).

5. Нечаев А.В., Поляков Е.Г. Состояние и перспективы рециклинга редкоземельных элементов // Труды Кольского научного центра РАН. - 2018. - С. 75-80.

6. Проект Стратегии развития промышленности редких и редкоземельных металлов Российской Федерации на период до 2035 года // СПС Гарант.

7. Сергеев И.Б., Пономаренко Т.В. Стимулы создания конкурентоспособной редкоземельной промышленности в России в условиях глобальной конкуренции // Записки Горного института. - 2015. - Т. 211. C. 104-115.

8. Темнов А.В., Азарнова Л.А. Роль редких металлов в ресурсном обеспечении стратегическими и критическими видами минерального сырья ведущих зарубежных стран// Минеральные ресурсы России. Экономика и управление. - 2016. — №1 (2). — С. 100-106. 
9. Черный С. Вторичные ресурсы редкоземельных металлов // Экология и промышленность России. - 2020. - 24 (9). C. 44-50.

10. Яценко В.А., Самсонов Н.Ю., Крюков Я. В. Особенности мирового рынка редкоземельных металлов // Минеральные ресурсы России. - 2018. - №6. - С. 68-72.

11. Abraham D.S. The Elements of Power: Gadgets, Guns, and the Struggle for a Sustainable Future in the Rare Metal Age Paperback. Yale University Press, 2015. - 336 p.

12. Balaram $V$. Rare earth elements: A review of applications, occurrence, exploration, analysis, recycling, and environmental impact// Geoscience Frontiers. - 2019. - Vol. 10 (4). Pp. 285-1303.

13. Calas $G$. Mineral resources and sustainable development // Elements. — 2017. Vol. 13. - Pp. 301-306.

14. Communication from the commission to the European parliament, the council, the European economic and social committee and the committee of the regions on the 2017 list of Critical Raw Materials for the EU [Electronic resource] // European Commission, Brussels, 2017. - URL: https://eur-lex.europa.eu/legalcontent/EN/TXT/PDF/?uri=CELEX:52017DC0 490\&from=EN (Date accessed: 17.12.2020).

15. Does China Pose a Threat to Global Rare Earth Supply Chains? [Electronic resource]// China Power. - URL: https://chinapower. csis.org/china-rare-earths/ (Date accessed: 25.12.2020).

16. Future Supply of Rare Earth Elements. Overview [Electronic resource] // IPC. - URL: http://www.ipc.org/ContentPage. aspx?pageid=future-supply-of-rare-earth-elements (Date accessed: 24.12.2020).

17. Global Rare Earth Metals Market Will Reach USD 14.43 Billion By 2025: Zion Market Research. - 2019. [Electronic resource]. URL: https://www.globenewswire.com/newsrelease/2019/04/16/1804623/0/en/Global-RareEarth-Metals-Market-Will-Reach-USD-14-43Billion-By-2025-Zion-Market-Research.html (Date accessed: 24.01.2021).

18. Goodenough K.M., Wall F., Merriman $D$. The Rare Earth Elements: Demand, Global Resources, and Challenges for Resourcing Future Generations // Natural Resources Research. — 2018. — №27 (1). — Pp. 201-216.
19. Huleatt M.B. Australian Resource Reviews: Rare Earth Elements 2019 [Electronic resource] // Geoscience Australia, Canberra. URL: https://ecat.ga.gov.au/geonetwork/srv/ eng/catalog.search\#/metadata/130434 (Date accessed: 24.01.2021).

20. Massari S., Ruberti M. Rare earth elements as critical raw materials: Focus on international markets and future strategies // Resources Policy. — 2013. — №38 (1). — Pp. 36-43.

21. Nassar N., Xiaoyue D., Graedel T. Criticality of the Rare Earth Elements // Journal of Industrial Ecology 2015. — №19 (6). Pp. 1044-1054.

22. Paris Agreement. European Comission. Energy, climate change and Environment [Electronic resource]. — URL: https://ec.europa.eu/ clima/policies/international/negotiations/paris en (Date accessed: 25.10.2020).

23. Ponomarenko T.V., Nevskaya M.A., Marinina O.A. Complex use of mineral resources as a factor of the competitiveness of mining companies under the conditions of the global economy // International Journal of Mechanical Engineering and Technology. - 2018. №9. - Pp. 1215-1223.

24. Skirrow R.G., Huston D.L., Mernagh T.P., Thorne J.P., Dulfer H., Senior A.B. Critical commodities for a high-tech world: Australia's potential to supply global demand. Geoscience Australia, Canberra, 2013. - 127 p.

25. Special issue on rare earths. Rare earth elements: A review of production, processing, recycling, and associated environmental issues [Electronic resource] // UNCTAD, 2014. - URL: www.unctad.org/en/PublicationsLibrary/suc2014d1_en.pdf (Date accessed: 25.12.2020).

26. Takeda O., Okabe T.H. Current Status on Resource and Recycling Technology for Rare Earths // Metallurgical and Materials Transactions E. - 2014. - №1 (2). - Pp. 160-173.

27. The rare earth Magazine [Electronic resource]. — URL: http://rareearth.ru/ (Date accessed: 10.01.2021).

28. Tsvetkova A. Y., Katysheva E. G. Present problems of mineral and raw materials resources replenishment in Russia // Albena Bulgaria: SGEM. - 2019. — Vol. 19. - Pp. 573-578.

29. U. S. Geological Survey, 2020. Mineral commodity summaries [Electronic resource] // U.S. Geological Survey. - Режим доступа: 
https://pubs.er.usgs.gov/publication/mcs 2020 (Date accessed: 12.01.2021).

30. Umbach $F$. Uncertain strategies for securing supplies of critical raw materials [Electronic resource] // Geopolitical Intelligence Services. - URL: https://www.gisreportsonline. com/uncertain-strategies-for-securing-suppliesof-critical-raw-materials-energy-2597-report. html (Date accessed: 08.01.2021).

\section{References}

1. Gasanov A.A., Naumov A.V., Jurasova O.V., Petrov I.M., Litvinova T.E. Nekotorye tendencii mirovogo rynka RZM i perspektivy Rossii // Izvestija vuzov. Cvetnaja metallurgija [Some trends of the world market of REM and prospects of Russia. Non-ferrous metallurgy]. 2018. — №4. — Pp. 31-44.

2. Eremin N.I. Kriticheskoe mineral'noe syr'e v jekonomikah vedushhih promyshlennorazvityh stran [Critical mineral raw materials in the leading economies of the industrialized countries] // Materialy konferencii «Mestorozhdenija strategicheskih metallov», IGEM RAN [Materials of the conference «Deposits of strategic metals», IGEM RAS]. — 2015. — Pp. 48-56.

3. Kondrat'ev V.B. Global'nyj rynok redkozemel'nyh metallov [The Global market for rare earth metals] // Gornaja promyshlennost' [Mining industry]. — 2017. — №4 (134). Pp. 97-119.

4. Minpromtorg RF. Oficial'nyj sajt [Ministry of Industry and Trade of the Russian Federation. Official website] [Jelektronnyj resurs]. URL: https://gisp.gov.ru/new_user/ (Date accessed: 12.12.2020).

5. Nechaev A. V., Poljakov E. G. Sostojanie i perspektivy reciklinga redkozemel'nyh jelementov [The State and prospects of recycling rare earth elements] // Trudy Kol'skogo nauchnogo centra RAN [Proceedings of the Kola scientific center of RAS]. - 2018. - Pp. 75-80.

6. Proekt Strategii razvitija promyshlennosti redkih i redkozemel'nyh metallov Rossijskoj Federacii na period do 2035 goda [The project of Strategy of development of the industry of rare earth metals of the Russian Federation for the period till 2035] // SPS Garant.

7. Sergeev I. B., Ponomarenko T. V. Stimuly sozdanija konkurentosposobnoj redkozemel'noj promyshlennosti v Rossii v uslovijah global'noj konkurencii [Stimuli for creating a competitive rare-earth industry in Russia in the context of global competition] // Zapiski Gornogo instituta. - 2015. - Vol. 211. - Pp. 104-115.

8. Temnov A.V., Azarnova L.A. Rol' redkih metallov $\mathrm{v}$ resursnom obespechenii strategicheskimi i kriticheskimi vidami mineral'nogo syr'ja vedushhih zarubezhnyh stran [The role of rare metals in resource provision with strategic and critical types of mineral raw materials of leading foreign countries] // Mineral'nye resursy Rossii. Jekonomika i upravlenie [Mineral Resources of Russia. Economics and Management]. — 2016. — №1 (2). — Pp. 100-106.

9. Chernyj S. Vtorichnye resursy redkozemel'nyh metallov [Secondary resources of rare earth metals] // Jekologija i promyshlennost' Rossii [Ecology and Industry of Russia]. 2020. - 24 (9). - Pp. 44-50.

10. JacenkoV.A., Samsonov N. Ju., Krjukov Ja. $V$. Osobennosti mirovogo rynka redkozemel'nyh metallov [Features of the world market of rare earth metals] // Mineral'nye resursy Rossii [Mineral resources of Russia]. 2018. - №6. - Pp. 68-72.

11. Abraham D.S. The Elements of Power: Gadgets, Guns, and the Struggle for a Sustainable Future in the Rare Metal Age Paperback. Yale University Press, 2015. - 336 p.

12. Balaram $V$. Rare earth elements: A review of applications, occurrence, exploration, analysis, recycling, and environmental impact// Geoscience Frontiers. - 2019. — Vol. 10 (4). Pp. 285-1303.

13. Calas $G$. Mineral resources and sustainable development // Elements. - 2017. Vol. 13. - Pp. 301-306.

14. Communication from the commission to the European parliament, the council, the European economic and social committee and the committee of the regions on the 2017 list of Critical Raw Materials for the EU [Electronic resource] // European Commission, Brussels, 2017. — URL: https://eur-lex. europa.eu/legal-content/EN/TXT/PDF/?uri= CELEX:52017DC0490\&from=EN (Date accessed: 17.12.2020).

15. Does China Pose a Threat to Global Rare Earth Supply Chains? [Electronic resource]// China Power. - URL: https://chinapower. csis.org/china-rare-earths/ (Date accessed: 25.12.2020). 
16. Future Supply of Rare Earth Elements. Overview [Electronic resource] // IPC. - URL: http://www.ipc.org/ContentPage. aspx?pageid=future-supply-of-rare-earth-elements (Date accessed: 24.12.2020).

17. Global Rare Earth Metals Market Will Reach USD 14.43 Billion By 2025: Zion Market Research. - 2019. [Electronic resource]. URL: https://www.globenewswire.com/newsrelease/2019/04/16/1804623/0/en/Global-RareEarth-Metals-Market-Will-Reach-USD-14-43Billion-By-2025-Zion-Market-Research.html (Date accessed: 24.01.2021).

18. Goodenough K.M., Wall F., Merriman D. The Rare Earth Elements: Demand, Global Resources, and Challenges for Resourcing Future Generations // Natural Resources Research. — 2018. — №27 (1). — Pp. 201-216.

19. Huleatt M.B. Australian Resource Reviews: Rare Earth Elements 2019 [Electronic resource] // Geoscience Australia, Canberra. URL: https://ecat.ga.gov.au/geonetwork/srv/ eng/catalog.search\#/metadata/130434 (Date accessed: 24.01.2021).

20. Massari S., Ruberti M. Rare earth elements as critical raw materials: Focus on international markets and future strategies // Resources Policy. — 2013. - №38 (1). — Pp. 36-43.

21. Nassar N., Xiaoyue D., Graedel T. Criticality of the Rare Earth Elements // Journal of Industrial Ecology 2015. — №19 (6). Pp. 1044-1054.

22. Paris Agreement. European Comission. Energy, climate change and Environment [Electronic resource]. - URL: https://ec.europa.eu/ clima/policies/international/negotiations/paris en (Date accessed: 25.10.2020).

23. Ponomarenko T.V., Nevskaya M.A., Marinina O.A. Complex use of mineral resourc- es as a factor of the competitiveness of mining companies under the conditions of the global economy // International Journal of Mechanical Engineering and Technology. — 2018. №9. - Pp. 1215-1223.

24. Skirrow R.G., Huston D.L., Mernagh T.P., Thorne J.P., Dulfer H., Senior A.B. Critical commodities for a high-tech world: Australia's potential to supply global demand. Geoscience Australia, Canberra, 2013. - 127 p.

25. Special issue on rare earths. Rare earth elements: A review of production, processing, recycling, and associated environmental issues [Electronic resource] // UNCTAD, 2014. URL: www.unctad.org/en/PublicationsLibrary/ suc2014d1_en.pdf (Date accessed: 25.12.2020).

26. Takeda O., Okabe T.H. Current Status on Resource and Recycling Technology for Rare Earths // Metallurgical and Materials Transactions E. — 2014. — №1 (2). — Pp. 160.

27. The rare earth Magazine [Electronic resource]. — URL: http://rareearth.ru/ (Date accessed: 10.01.2021).

28. Tsvetkova A. Y., Katysheva E. G. Present problems of mineral and raw materials resources replenishment in Russia // Albena Bulgaria: SGEM. - 2019. - Vol. 19. - Pp. 573-578.

29. U. S. Geological Survey, 2020. Mineral commodity summaries [Electronic resource] // U.S. Geological Survey. - Режим доступа: https://pubs.er.usgs.gov/publication/mcs2020 (Date accessed: 12.01.2021).

30. Umbach $F$. Uncertain strategies for securing supplies of critical raw materials [Electronic resource] // Geopolitical Intelligence Services. - URL: https://www.gisreportsonline. com/uncertain-strategies-for-securing-suppliesof-critical-raw-materials-energy-2597-report. html (Date accessed: 08.01.2021). 


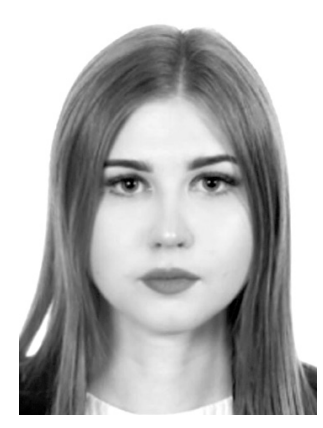

Соловьева Виктория Максимовна - аспирант кафедры «Экономика организации и управления» экономического факультета Санкт-Петербургского горного университета. Область научных интересов: стратегическое планирование и прогнозирование развития промышленно-сырьевых комплексов.

Solovyova Victoria Maksimovna - Postgraduate student, Department of Economics, Organization and Management, Saint Petersburg Mining University. Research interests: strategic planning and forecasting of the industrial and raw material complexes' development.

199106, г. Санкт-Петербург, Васильевский о-в, 21 линия, 2

2 21st Line, Vasilevsky isl., 199106, Saint Petersburg, Russia

E-mail: vikasolovyova9@gmail.com

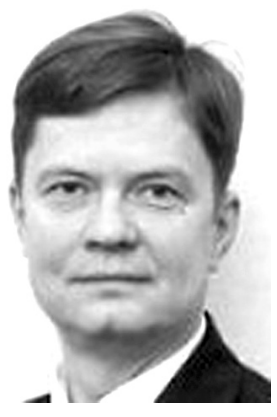

Череповицын Алексей Евгеньевич - доктор экономических наук, профессор, заведующий кафедрой «Экономика организации и управления» Санкт-Петербургского горного университета. Область научных интересов: стратегическое управление минерально-сырьевым комплексом, экономическая оценка инвестиционных проектов, экономико-правовые основы недропользования.

Cherepovitsyn Alexey Evgenievich - Doctor of Economic Sciences, Professor, the Head of the Department of Economics, Organization and Management, Saint Petersburg Mining University. Research interests: strategic management of the mineral resource complex, economic assessment of investment projects, economic and legal foundations of subsoil use.

199106, г. Санкт-Петербург, Васильевский о-в, 21 линия, 2 2 21st Line, Vasilevsky isl., 199106, Saint Petersburg, Russia

E-mail: alekseicherepov@inbox.ru 